\title{
Toxocariosis humana: seroprevalencia en población de Lima mediante la técnica de ELISA
}

\author{
YRMA ESPINOZA ${ }^{1,2}$, PEDRO HUAPAYA ${ }^{1,2}$, CARLOS SEVILLA $^{2}$, ALINA HUIZA $^{1,2}$, \\ SUSANA JIMÉNEZ², CÉSAR NÁQUIRA ${ }^{1,3}$ \\ ${ }^{1}$ Instituto de Medicina Tropical "Daniel A. Carrión”-UNSMM. ${ }^{2}$ Departamento Académico \\ de Microbiología Médica, Facultad de Medicina-UNMSM. ${ }^{3}$ Instituto Nacional de Salud.
}

\begin{abstract}
RESUMEN
OBJETIVO: Estimar la seroprevalencia de toxocariosis humana en población de la ciudad de Lima. Diseño: estudio transversal, la selección fue no aleatoria. MATERIAL Y MÉTODOS: En pobladores de la ciudad de Lima que pertenecían a comunidades urbano marginales, se realizó entrevista y examen clínico, y se obtuvo una muestra de suero para procesar la técnica de ELISA para detectar anticuerpos contra Toxocara. También, se solicitó muestras de heces para buscar parásitos intestinales que pudieran originar reacciones cruzadas en la serología. RESULTADOS: Se examinó 553 personas, siendo 23,3\% de ellos reactivos. No hubo diferencias en cuanto a sexo ni entre el resultado de ELISA y la presencia de anemia, leucocitosis, eosinofilia y parásitos intestinales. Los mayores de 15 años tuvieron doble probabilidad de resultar reactivos que los menores de 15 años. Disminución de la agudeza visual fue el síntoma más frecuente en los sujetos reactivos. Los parásitos intestinales más frecuentes fueron Blastocystis hominis, Entamoeba coli, Giardia lamblia. CONCLUSIONES: La toxocariosis humana es frecuente en la población de Lima. No se observa asociación estadística entre el hallazgo de anemia y alteraciones de la fórmula leucocitaria con el resultado de ELISA. Es necesario desarrollar programas de difusión para detectar precozmente la infección y así prevenirla.
\end{abstract}

Palabras clave: Toxocariasis; diagnóstico de laboratorio; ELISA; inmunosorbentes.

\section{HUMAN TOXOCARIOSIS: SEROPREVALENCE IN LIMA INHABITANTS BY ELISA TECHNIQUE \\ SUMMARY}

OBJECTIVE: To estimate seroprevalence of human toxocariosis in Lima inhabitants. DESIGN: Cross-sectional study, non aleatory selection. MATERIAL AND METHODS: To people living in Lima city urban marginal communities, an interview and clinical examination were done and serum samples obtained to detect antibodies against Toxocara by ELISA technique. Stool samples were also obtained to check parasites causing cross reactions with serology. RESULTS: From 553 persons examined 23,3\% were reactive. There were no sex differences and ELISA results related to anemia, leucocytosis, eosinophilia or intestinal parasites. People older than 15 yearold had twice the possibility to be reactive. Most frequent symptom in positive individuals was decrease of visual capacity. Most frequent parasites were Blastocystis hominis, Entamoeba coli, Giardia lamblia. CONCLUSIONS: Human toxocariosis is frequent in Lima inhabitants. There is no statistical association between anemia and changes in leucocyte formula with ELISA result. It is necessary to develop diffusion programs for early infection detection and prevention.

Key words: Toxocariasis; diagnosis, laboratory; enzyme-linked immunosorbent assay; immunosorbents.

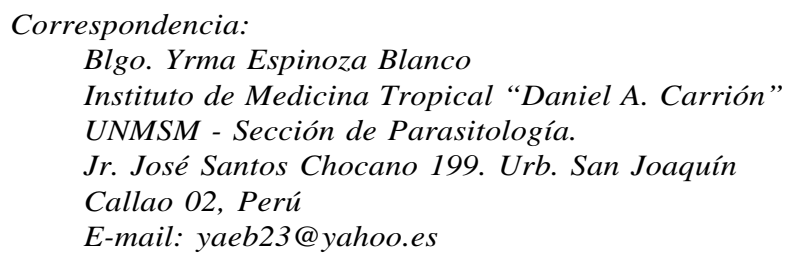




\section{INTRODUCCIÓN}

La toxocariosis es una enfermedad parasitaria accidental en el hombre, que se produce por la ingestión de huevos larvados del nemátodo del perro, Toxocara canis, y luego las larvas liberadas en el intestino migran hacia los tejidos ${ }^{(1-3)}$. Clínicamente se manifiesta en dos formas, visceral y ocular, siendo esta última la que puede originar ceguera en $64,2 \%$ de los casos $\left({ }^{4-7}\right)$.

Esta infección es considerada como problema de salud mundial $\left({ }^{8-10}\right)$ y es relativamente frecuente en zonas de climas templados y tropicales de todos los continentes; principalmente en el ámbito urbano, se asocia con la presencia de huevos de Toxocara en el medio ambiente. Los lugares más contaminados son jardines, parques públicos y los terrenos de juego $\left({ }^{11,12}\right)$.

En nuestro país se ha realizado diferentes estudios para determinar el grado de infección canina por Toxocara, con diversos resultados. Por ejemplo, $31,9 \%$ de infección canina en diferentes distritos de Lima ( $\left.{ }^{13}\right) ; 27,7 \%$ en perros de San Juan de Lurigancho $\left({ }^{14}\right), 47 \%$ en Chincha Alta en el departamento de Ica $\left({ }^{15}\right)$. En el Cuzco, $44,7 \%$ de los perros estudiados presentaba la infección $\left({ }^{16}\right)$. En el distrito de Amarilis en Huánuco, $80,3 \%$ de perros estaban infectados $\left({ }^{17}\right)$. En resumen, la infección canina por este parásito es frecuente.

El grado de contaminación por huevos de Toxocara en parques públicos es alto. Se encontró en 8 de 10 parques de varios distritos de Lima huevos larvados viables $\left({ }^{13}\right)$. Se reporta $24 \%$ de contaminación por huevos de Toxocara $s p$. en 12 parques de Lima $\left({ }^{18}\right)$. En parques públicos del Cono Sur y del Cono Este de Lima, se encontró respectivamente $29,6 \%\left({ }^{19}\right)$ y $41 \%$ $\left({ }^{20}\right)$ contaminados con huevos de Toxocara en diferentes grados de evolución. El 40\% de áreas recreativas de varias localidades del Cuzco presentaba huevos de Toxocara sp. $\left({ }^{16}\right)$. Se investigó 17 parques del distrito de Amarilis en la ciudad de Huánuco y se encontró contaminación en $62,9 \%\left({ }^{21}\right)$. Por ello, se puede afirmar que la contaminación ambiental es también frecuente en diversas zonas de nuestro país.

El único trabajo en nuestro medio sobre seroprevalencia en población general fue realizado en 1991, encontrando $7,38 \%$ de positividad por la prueba de ELISA $\left({ }^{13}\right)$. La escasez de reportes se debe a la ausencia de métodos de diagnóstico de esta infección en nuestro país.

La infección humana por Toxocara es un problema de salud mundial, que se busca sólo en sujetos sintomáticos, principalmente con afecciones oftalmológicas crónicas. Sin embargo, luego de encontrar que los huevos del parásito, que constituyen la forma infectante para el ser humano, están diseminados en el medio ambiente de varias ciudades del Perú, principalmente en la ciudad de Lima, y que las manifestaciones clínicas se producen después de una larga evolución, es importante estimar la prevalencia de la infección en la población general, para conocer la magnitud del problema, identificar la cadena epidemiológica de la infección, estudiar las manifestaciones clínicas que pueda producir y proponer las medidas preventivas o de control.

\section{MATERIAL Y MÉTODOS}

Se realizó un estudio exploratorio de tipo transversal. La selección de sujetos se efectuó en forma no aleatoria. Para ello se invitó a participar a un grupo de pobladores de la ciudad de Lima que pertenecían a comedores parroquiales (Comedores de la Orden Santísima Trinidad de Ancón y Puente Piedra y comedores "Jesús Rescatado" y "Virgen del Carmen" del Cercado de Lima) y el Asentamiento Humano "Los Próceres" de Ventanilla, Callao, quienes participaron de actividades de proyección a la comunidad realizada por el personal de la Sección de Parasitología del Instituto de Medicina Tropical "Daniel A. Carrión"UNMSM (IMTDAC). También se invitó a 
pacientes que acudían al IMTDAC para consulta por diversos problemas no asociados a la infección.

Todos los participantes fueron entrevistados para determinar la presencia de factores asociados a la infección y se realizó examen clínico general. Asimismo se obtuvo una muestra de sangre de aproximadamente $8 \mathrm{~mL}$ de cada individuo, que se dividió en 2 alícuotas: $5 \mathrm{~mL}$ para la obtención de suero y $3 \mathrm{~mL}$ con anticoagulante para realizar el recuento de leucocitos y la fórmula diferencial.

Las muestras de suero fueron procesadas mediante la técnica de ELISA para detectar anticuerpos específicos contra Toxocara, mediante el método estandarizado en el IMTDAC en estudio previo $\left({ }^{22}\right)$.

También, se solicitó dos muestras de heces de cada individuo, que fueron procesadas para buscar parásitos intestinales que pudieran originar reacciones cruzadas en el examen serológico.

Los resultados fueron almacenados en una base de datos elaborada con la hoja de cálculo
Excel y el análisis estadístico se realizó con el paquete estadístico SPSS 9,0. Para ello, se elaboró tablas de frecuencias, se buscó diferencias en la distribución de individuos en cada factor estudiado, tanto clínico, epidemiológico o presencia de agente concomitante con respecto al resultado de la prueba inmunológica; estas diferencias fueron verificadas mediante la prueba de $\mathrm{X}^{2}$ y se calculó la razón de probabilidades (OR) para estimar la fuerza de la asociación.

\section{RESULTADOS}

Se examinó 553 individuos cuya distribución por edades y lugar de procedencia se muestra en la Tabla 1. Resultaron reactivos $23,3 \%$, mientras que $17,9 \%$ fueron calificados como sospechosos, pues su resultado coincidió con el valor del punto de corte; por lo que se requiere un segundo examen de esta población para determinar su condición definitiva (Tabla 2). No hubo diferencias en cuanto a sexos, tampoco hubo asociación estadística entre el resultado de ELISA y la presencia de anemia, leucocitosis, eosinofilia y parásitos intestinales. Se observó

Tabla 1.- Distribución de edades de los participantes según establecimiento.

\begin{tabular}{|c|c|c|c|c|c|c|c|c|}
\hline \multirow[t]{2}{*}{ Edades } & \multirow[t]{2}{*}{ Ancón } & \multirow[t]{2}{*}{$\mathrm{PP}$} & \multirow[t]{2}{*}{ Rescate } & \multirow[t]{2}{*}{$\mathrm{V}$ de $\mathrm{C}$} & \multirow[t]{2}{*}{ IMT } & \multirow[t]{2}{*}{ Próceres } & \multicolumn{2}{|c|}{ Total } \\
\hline & & & & & & & $\mathrm{n}$ & $\%$ \\
\hline$<1$ año & 0 & 3 & 0 & 0 & 1 & 0 & 4 & 0,7 \\
\hline $1-4$ años & 14 & 12 & 25 & 9 & 5 & 25 & 90 & 16,3 \\
\hline $5-14$ años & 50 & 44 & 35 & 20 & 22 & 38 & 209 & 37,8 \\
\hline 15 - 44 años & 3 & 20 & 27 & 14 & 92 & 45 & 201 & 36,4 \\
\hline 45 - 60 años & & 2 & 2 & 0 & 15 & 2 & 21 & 3,8 \\
\hline$>60$ años & & 0 & 0 & 0 & 12 & 0 & 12 & 2,2 \\
\hline Sin dato & & 0 & 0 & 0 & 7 & 9 & 16 & 2,9 \\
\hline Total & 67 & 81 & 89 & 43 & 154 & 119 & 553 & 100,0 \\
\hline
\end{tabular}

Ancón: Comedor de la Orden Santísima Trinidad de Ancón.

PP: Comedor de la Orden Santísima Trinidad de Puente Piedra.

Rescate: Comedor "Jesús Rescatado" de la Orden Santísima Trinidad-Cercado de Lima.

$V$ de C: Comedor "Virgen del Carmen" de la Orden Santísima Trinidad-Cercado de Lima.

IMT: Instituto de Medicina Tropical "Daniel A. Carrión” - UNMSM.

Próceres: Asentamiento Humano "Los Próceres" - Ventanilla. 
Tabla 2.- Resultados de ELISA en el grupo de estudio.

\begin{tabular}{lrr}
\hline Resultado & $\mathrm{n}$ & $\%$ \\
\hline Reactivo & 129 & 23,3 \\
No Reactivo & 325 & 58,8 \\
Sospechoso* $^{*}$ & 99 & 17,9 \\
Total & 553 & 100,0 \\
\hline
\end{tabular}

* Resultado coincide con el punto de corte, requiere segunda evaluación.

que el grupo mayor de 15 años, tuvo doble probabilidad de resultar positivo que el grupo menor de 15 años (Tabla 3). La disminución de la agudeza visual fue el síntoma más frecuentemente descrito por los sujetos reactivos. Los parásitos intestinales más frecuentes fueron Blastocystis hominis, Entamoeba coli, Giardia lamblia en todo el grupo estudiado.

\section{DISCUSIÓN}

Los resultados obtenidos permiten estimar que la prevalencia de la infección humana por Toxocara canis es alta, lo cual coincide con varios reportes internacionales $\left({ }^{23}\right)$ mientras que contrasta con otros. Así tenemos estudios realizados en Brasil y Argentina en niños, con $37 \%$ a $39 \%$ de positividad $\left({ }^{24,25}\right)$. Otro reporte de Argentina en población general también indica $39 \%$ de positivos $\left({ }^{26}\right)$ y otro de Nigeria $29 \%\left({ }^{27}\right)$. El único reporte realizado en población nacional llegó a alrededor de $7 \%\left({ }^{13}\right)$.

Tabla 3.- Resultados de ELISA por edades.

\begin{tabular}{lcccccc}
\hline \multirow{2}{*}{ Edades } & \multicolumn{2}{c}{ Reactivo } & & \multicolumn{2}{c}{ No Reactivo } & \multirow{2}{*}{ Total } \\
\cline { 2 - 3 } & $\mathrm{n}$ & $\%$ & & $\mathrm{n}$ & $\%$ & \\
\hline$<15$ años & 70 & 54,3 & & 119 & 36,6 & 189 \\
$>15$ años & 59 & 457 & & 206 & 63,4 & 265 \\
Total & 129 & 100,0 & & 325 & 100,0 & 454 \\
\hline
\end{tabular}

$O R=2,05(1,33-3,17), p=0,0008$.
Es de resaltar que la infección es frecuente en sujetos relativamente jóvenes o en edad productiva, con énfasis en personas mayores de 15 años, lo cual evidencia que la infección inicial se produce durante la infancia, ya que existen reportes de la historia natural de la enfermedad en ese sentido $\left({ }^{1,3,5,10}\right)$.

No se observó asociación entre el resultado positivo y el hallazgo de anemia y leucocitosis, lo que coincide con la bibliografía $\left({ }^{1-4,25,26}\right)$. Tampoco se encontró asociación con eosinofilia, que es un dato clínico útil para la sospecha de la infección visceral mas no ocular. El no haberla encontrado en el grupo estudiado y la presencia frecuente de disminución de agudeza ocular, permite estimar que los casos positivos tendrían la infección ocular aún silente o infección visceral con poca actividad, de tal forma que no ocasiona eosinofilia

Podemos concluir que la toxocariosis humana es frecuente en la población de Lima $(23,3 \%)$ y la mayoría de los participantes manifestó ser asintomáticos. Es necesario desarrollar programas de difusión para detectar precozmente la infección, así como para prevenirla.

\section{BIBLIOGRAFÍA}

1. Minvielle M, Niedfeld M, Ciarmela M y Basualdo J. Toxocariosis causada por Toxocara canis aspectos epidemiológicos. Enf Infec Microbiol Clin 1999; 17; 3006.

2. Agudelo C, Villareal E, Cáceres E, López C, Eljach J, Ramírez N, et al. Human and dogs Toxocara canis infection in a poor neighborhood in Bogota. Mem Inst Oswaldo Cruz, Rio de Janeiro 1990; 85 (1): 75-8.

3. Noemi I, Viovy A, Cerva J, Gottlieb B, Roncone E, Quera $\mathbf{R}$, et al. Perfil clínico de la toxocariasis en pediatría. Parasitol al Día 1992; 16: 91-7.

4. Beaver C, Snyder H, Carrera M, Dent H, Lafferty W. Chronic eosinophilia due to Visceral Larva Migrans. Pediatrics 1952; 9: 7-19.

5. Nichols L. The etiology of visceral larva migrans. J Parasitol 1956; 42: 349-62.

6. Miranda-Souza A, Alzamora B, Maguiña C, Tobaru L, Yarlequé C, Terashima A, et al. Primer reporte en el Perú de Toxocariasis ocular: análisis de 21 casos. Bol Soc Peruana Med Interna 1999; 12: 20-8. 
7. Montesinos B, Delgado J, Ayala E, Alvarez J, Hernández M, Delgado J, et al. Casos clínicos toxocariasis ocular. A propósito de un caso. Arch Soc Canar Oftal 2000 - No. 11.

8. Taylor M, Keane C, O'Connor P, Mullvihil E, Holand C. The expanded espectrum of toxocaral disease. Lancet 1988; 1: 692-5.

9. Portus M, Riera C. Prats G. A serological survey of toxocariosis in patients and healthy donors in Barcelona (Spain) . Eur J Epidemiol 1989; 5: 224-7.

10. Matos Mde F, Militao DN, Brum MA, Omais M, Quiliao ME, Dorval ME, et al. Presence of anti-Toxocara antibodies in children selected at hospital universitario, Campo Grande. Rev Inst Med Trop Sao Paulo 1997; 39(1): 49-50.

11. Alvares V, Sartor I, Marsubara F. Contaminãçao por ovos de Toxocara spp. de parques e praças públicas de Botucatu, Sao Paulo, Brasil. Rev Soc Brasileira Med Trop 1998; 31(6): 529-32.

12. Canese A, Orué ME, Paciello ML, Rodríguez H. Huevos infectivos de Toxocara en el suelo de la ciudad de Asunción, Paraguay. Rev Paraguaya Microbiol 1999; 19 (1).

13. Zevallos S, Chieffi P, Peres B, Mello E, Náquira C, Apaza A, et al. Soil contamination and human infection by Toxocara sp. in the urban area of Lima, Peru. Mem. Inst. Oswaldo Cruz, Rio de Janeiro 1998; 93(6): 733-4.

14. García E. Prevalencia de Helmintos gastrointestinales en Canis familiaris en el distrito de Lurigancho, Chosica, Dpto. de Lima. [Tesis Bachiller en Medicina Veterinaria]. Lima: Universidad Nacional Mayor de San Marcos; 2001.

15. Dávalos M, Pachas O, Pérez V. Toxocariosis en Canis familiares y suelo en el distrito de Chincha alta (1998-1999). IV Congreso Peruano de Parasitología, Septiembre 2000, Lima, Perú, resumen 152, p. 215.

16. Rodríguez V, Muñiz F. Toxocara canis en excretas de perros, suelos y vegetales de calles, plazas y áreas recreacionales de Cuzco urbano. IV Congreso Peruano de Parasitología Septiembre 2000. Lima Perú, resumen 161, p. 224.

17. Rafael F. Prevalencia de Toxocara sp. en caninos del distrito de Amarilis. [Tesis para optar el título de médico veterinario]. Huánuco: Universidad Hermilio Valdizán; 2000.

18. Guerrero M. Estudio de la contaminación de parques públicos de Lima Metropolitana con huevos de Toxocara $s p$. Tesis de Bachiller en Medicina Veterinaria, Universidad de San Marcos, Lima - 1975.

19. Cajas J, Chávez A, Casas E. Prevalencia de huevos de Toxocara spp en parques públicos del cono sur de Lima metropolitana. IV Congreso Peruano de Parasitología Septiembre 2000. Lima Perú, resumen 170, p. 233.

20. Serrano M, Chávez A, Casas E. Toxocariosis en parques del cono este de Lima. IV Congreso Peruano de Parasitología Septiembre 2000. Lima Perú, resumen 35, p. 239.

21. Pujay C. Estudio de la contaminación de parques públicos con huevos de Toxocara sp. En el distrito de Amarilis. Huánuco. Tesis Universidad Hermilio Valdizán 2000.

22. Espinoza Y, Huapaya P, Huiza A, Sevilla C, Náquira C, Alva P, et al. Estandarización de la técnica de ELISA para el diagnóstico de Toxocariosis humana. Anal Fac Med 2003; 64(1): 7-12.

23. Jimenez J, Valladares B, Fernandez-Palacios J, De Armas F, Del Castillo A. A serologic study of human toxocariasis in the Canary Islands (Spain): Environmental influences. Am J Trop Med Hyg 1997; 56(1): 113-5.

24. Moreira S, Leao M, Mendonca H, Pereira F. Prevalence of anti-Toxocara antibodies in a random sample of inpatients at a children's hospital in Vitoria, Espírito Santo, Brazil. Rev Inst Med Trop S Paulo 1998; 40(4): 259-61.

25. Alonso J, Bojanich M, Chamorro M, Gorodner J. Toxocara seroprevalence in children from a subtropical city in Argentina. Rev Inst Med Trop S Paulo 2000; 42 (4): 235-7.

26. Radman N, Archelli S, Fonrouge R, Guardis M, Linzitto O. Human Toxocariosis. Its seroprevalence in the city of La Plata. Mem Inst Oswaldo Cruz, Rio de Janeiro 2000; 95(3): 281-5.

27. Ajayi O, Duhlinska D, Agwale S, Njoku M. Frequency of human toxocariasis in Jos, Plateau State, Nigeria. Mem. Inst. Oswaldo Cruz, Rio de Janeiro 2000; 95(2): 147-9. 